\title{
Senecio Vukotinovici Schloss. n. sp.
}

\author{
Von Dr. J. C. Schlosser Ritt. v. Klekovski.
}

Inflorescentia primum densa, corymbosa, serius racemosopaniculata, demum ramosissima; capitula supra basin angustata, conoidea, elongata; squamae anthodii anguste lanceolatae, dorso elevatae, striatae marginibus hyalinis, apice sphacelatae, laete virides, nitidulae, flores discoidei, pallidae flavescentes; achenia striata, utrinque attenuata, basi coarctata, annulo calloso cincta; pappus sericeus, plumosus, mollis.

Caulis strictus, teres, striatus, fragilis, foliosissimus, glabriusculus, inferne pubescens, vel sparsim pilosellus, simplex vel superne ramosus, vel demum ex axillis foliorum inferionum ramulos corymbosos edens, basi praemorsus et circa circum radioulas inerassatas, fibrosas in densam conam complicatas proferens.

Folia radicalia primigena breviuscula, ovali-acuta, denticulata, sequentia et caulina lanceolata, arrecta, incequaliter et erroso- aut runcinato-dentata, dentibus apiculo calloso mucronuli instar terminatis, subtus crasse venosa, ad costam mediam et in margine scabriuscula, breviter ciliolata, apice acutiuscula, basi cordata, adhaerente auriculata; folia superiora linearilanceolata, demum linearia, integra, vel basi solum incisa et hastata, suprema tandem filiformia, ciliolata, squamarum instar in pedunculis disposita et capitulis calyculi laxi instar adnata; radix ut supra; planta annua. $\odot$ Flor. mense Julio et Augusto.

Diese für die Flora Croatiens und aller Wahrscheinlichkeit nach auch für das weitere Flora-Gebiet neue Pflanzenart wurde von Herrn v. Vukotinović bereits im Jahre 1876 auf einer Steckenwald-Rodung der benachbarten Agramer Weingarten-Berge in einigen $(3-4)$ Exemplaren gefunden; jedoch in den folgenden Jahren ohne Erfolg gesucht, indem die Ausrodung mit Weinreben bepflanzt werde. Erst im Sommer (20. Juli) 1880 gelang es uns, diese "KreuzkrautArt" auf einer Eichenwaldausrodung (vom J. 1878) im erzbischöflichen Parke "Maximir" nächst Agram wieder zu finden, wo solche in Gesellschaft von Senecio sylvatious L., Erigeron eanadensis L., Epilobium virgatum Fries, Centaurea stenolepis Kerner, Molinia littoralis Host u. s. w. massenhaft vorgefunden wurde.

Ich widme diese interessante Pflanzenart meinem Freunde und trenen Gefährten auf dem Gebiete der "Scientia amabilis", Herm Ludwig v. Vukotinović, und wünsche, dass sie als solche anerkannt und benannt werde.

Agram, den 27. November 1880. 